\title{
A CONSTRUÇÃO DA PROFISSIONALIDADE DOCENTE PARA A EDUCAÇÃO PROFISSIONAL: ANÁLISE DE CONCURSOS PÚBLICOS PARA DOCENTE
}

\author{
S. P. S. CRUZ ${ }^{1}$ e T. R. S. VITAL ${ }^{2}$ \\ Universidade de Brasília \\ shirleidesc@gmail.com ${ }^{1}$; taitaivital@gmail.com²
}

Artigo submetido em fevereiro/2014 e aceito em março/2014

\section{RESUMO}

O presente trabalho é parte integrante de uma pesquisa mais ampla sobre os elementos da construção da profissionalidade docente na educação profissional. Apresenta-se dados iniciais da análise desenvolvida a partir da caracterização dos editais e provas de concursos públicos dos Institutos Federais do Centro-oeste dentro do período de 2008 a 2012.Realizamos uma investigação a partir da tríade profissionalização-profissionalismoprofissionalidade desvelando como os requerimentos exigidos nos concursos se aproximam ou se distanciam de uma sólida construção da profissionalidade para atuar nessa modalidade. Identificou-se os seguintes aspectos: a) ênfase dada aos conhecimentos específicos em detrimento aos conhecimentos didático-pedagógicos, perpassando diferentes etapas dos certames b) a construção de um perfil de pesquisador para o docente e c) a precaridade gerada pela indefinição ou ambiguidade quanto à titulação básica, habilitação pela via da licenciatura e ou a realização de curso de mestrado e doutorado.

PALAVRAS-CHAVE: profissionalidade docente, concurso público, educação profissional.

\section{CONSTRUCTION OF PROFESSIONALISM FOR TEACHING PROFESSIONAL EDUCATION: ANALYSIS OF PUBLIC PROCUREMENT FOR TEACHERS}

\begin{abstract}
This work is part of a broader study about the elements of the construction of professional teaching in vocational education. It presents initial data analysis developed from the characterization of edicts and proof of procurement of Federal Institutes of Midwest within the period 2008 to 2012. Realizamos an investigation from the triad - professionalization professionalism professionality, revealing how the requirements required in procurement approach or move away from a solid
\end{abstract}

construction of professionality to act in this mode. We identified the following aspects : a) emphasis on expertise rather than the didactic and pedagogical knowledge, passing different stages of competitions $b$ ) building a profile for the teacher researcher and c) the uncertainty generated by vagueness or ambiguity as to the Basic titration , by way of qualification or degree and the completion of master's or PhD .

KEYWORDS: teacher professionality, open, professional education 


\section{INTRODUÇÃO}

O presente trabalho é parte integrante de uma pesquisa mais ampla que tem como objetivo analisar elementos da construção da profissionalidade docente na educação profissional técnica e tecnológica de licenciados e bacharéis. Desta feita, busca identificar os conhecimentos docentes exigidos nos concursos públicos e as práticas de formação continuada e em serviço que estão sendo desenvolvidas para docentes nas instituições federais no contexto da Rede federal de Educação Profissional instituída em 2008. Para efeito deste texto apresentamos os dados iniciais da análise desenvolvida a partir da caracterização dos editais e provas de concursos públicos dos Institutos Federais do Centro-oeste dentro do período de 2008 a 2012.

O tema da presente proposta de pesquisa tem relevância no contexto das recentes políticas implementadas para a educação profissional e tecnológica no nosso país. Machado (2011) nos aponta algumas dessas ações (expansão da Rede Federal de Educação, Cientifica e Tecnológica a partir de 2005, Programa Nacional de Acesso ao Ensino Técnico e Emprego- PRONATEC, o Plano Nacional de Educação- PNE 2011-2020, Programa Nacional de Integração da Educação Profissional a Educação Básica na Modalidade de Educação de Jovens e Adultos- PROEJA, o ensino médio integrado, dentre outras ações, são exemplos desse movimento) e também destaca a importância da formação de professores para que esse conjunto de ações se efetive com "qualidade social, produção de conhecimentos, valorização docente e desenvolvimento local, integrado e sustentável"(p. 690)

Historicamente, a formação docente para atuar na educação profissional esteve marcada por um caráter emergencial e aligeirado por meio de programas de complementação pedagógica sejam em cursos de licenciaturas curtas ou cursos de aperfeiçoamento. Esses aspectos, marcadamente, estiveram ligados à formação em serviço dos bacharéis. Desde a LDB 4024/61 já havia essa configuração com a indicação dos cursos especiais apontados em seu artigo 59. Além desse aspecto, tal indicação promovia uma separação entre a formação de docente para o ensino secundário geral, inclusive do curso normal, e a dos professores do ensino técnico em nível secundário. Aqueles primeiros seriam formados pelas Faculdades de Ciências e Letras, já os professores de disciplinas específicas do ensino técnico seriam formados nos referidos cursos especiais.

Esses cursos especiais tiverem uma definição própria a partir da Portaria no 432 publicada antes da reforma de ensino de 1 e e 2a graus, Lei 5692/71 que propôs a profissionalização compulsória no 2 grau, fato que em si, já demandava uma modificação na formação docente para o ensino profissionalizante. Assim, esses cursos forma denominados de Esquema I e II, ambos em nível superior que conferiam diploma de licenciatura para os bacharéis das diversas áreas do ensino técnico. A LDB 9394/96 não rompeu com a lógica existente nestes cursos, embora tenha extinguido a nomenclatura manteve a prerrogativa de que aos profissionais diplomados em nível superior e não licenciados, poderia ser dada a possibilidade de cursarem programas de formação pedagógica (art. 63, inciso II).

Seus princípios podem ser ainda encontrados na resolução no 2/97 que trata exatamente dos Programas especiais de formação pedagógica de docentes para as disciplinas do currículo do ensino fundamental, do ensino médio e da educação profissional em nível médio e apresenta uma 
lacuna até os dias de hoje por não detalhar de forma adequada como se daria a formação no contexto desses programas. Na resolução apenas se encontram o quantitativo de horas, mínimo de $540 \mathrm{~h}$, sendo que desta, $300 \mathrm{~h}$ serão destinadas à formação prática e apenas as 240 restantes seriam destinadas para o estudo teórico. Observa-se o limite de se pensar a formação docente de modo dicotômico com primazia para os aspectos práticos além da contradição de que o portador do certificado desses programas especiais receberia, de forma equivalente, a indicação de ter realizado uma licenciatura plena que, segundo resolução própria somente se integraliza com o mínimo de 2.800 .

No caso dos licenciados para atuarem com disciplinas do núcleo comum do currículo da educação básica quase nenhuma especificidade quanto ao trabalho com a formação profissional e contextualização desses conhecimentos ao mundo do trabalho tem sido feita. Muito embora para essa nossa última afirmação não se localiza uma produção científica sólida para lhe ratificar. Esta se baseia na observação empírica de conversas e práticas de professores das diversas áreas de conhecimento que lecionam na educação profissional, como também dos estudantes das licenciaturas diversas com as quais se tem contato nas disciplinas ministradas nos centros e faculdade de Educação (geralmente, Didática geral, Psicologia da Educação, Organização da Educação Brasileira e Políticas Públicas de Educação, dentre outras denominações).

Para Machado (2011) além desses aspectos legais existem ainda outras dimensões formativas que caminham para o campo epistemológico, pedagógico e social. Para ela

o desafio da formação de professores para a educação profissional manifesta-se de vários modos, principalmente quando se pensa nas novas necessidades e demandas político-pedagógicas dirigidas a eles: mais diálogos com o mundo do trabalho e a educação geral; praticas pedagógicas interdisciplinares e interculturais; enlaces fortes e fecundos entre tecnologia, ciência e cultura; processos de contextualização abrangentes; compreensão radical do que representa tomar o trabalho como principio educativo; perspectiva de emancipação do educando, porquanto sujeito de direitos e da palavra.

Analisamos a construção da profissionalidade docente na educação profissional, compreendendo que o conceito de profissionalidade é um conceito em construção. Nesse sentido, entendemos essa dinâmica de construção situada como uma dimensão da profissionalização que reflete uma relação entre os elementos de regulação social da profissão ${ }^{1}$ e os aspectos mais individuais dos sujeitos.

A análise da construção da profissionalidade docente têm se apresentado como um tema emergente no campo da pesquisa educacional. Segundo Ambrosetti e Almeida (2008) esses estudos buscam analisar a formação docente de forma contextualizada, superando as concepções normativas que, externamente, definem os critérios para o exercício profissional. Procura-se, assim, compreender a docência em sua mutltirreferencialidade, expressada nas diversas relações que os indivíduos estabelecem nos espaços sociais de construção da profissão.

\footnotetext{
${ }^{1}$ Tomamos o conceito de regulação a partir de Dourado (2007), citando Barroso (2006a, p.13) para descrever que esta expressa "dois tipos diferenciados de fenômeno, mas interdependentes: os modos como são produzidas e aplicadas as regras que orientam a ação dos atores; os modos como esses mesmos atores se apropriam delas e as transformam" (p. 922).
} 
Essa dinâmica demonstra ainda que o tema da profissionalidade não deve ser entendido de forma isolada da relação estabelecida pela tríade profissionalização-profissionalidadeprofissionalismo. Considera-se a profissionalização como um conjunto de ações historicamente situadas que definirão certos parâmetros para o exercício profissional docente que elevariam ainda a condição de uma determinada função social como uma profissão socialmente reconhecida. Já o profissionalismo remete aos aspectos que são referendados ou aderidos pelos sujeitos que exercem a profissão, de modo a definir um status social, dando, portanto, legitimidade para a função social que exercem.

Nesse processo, a profissionalidade retrata além dos saberes e competências definidos para o exercício profissional, as formas subjetivas que os profissionais vão constituindo na relação com os processos mais externos instituintes da profissionalização. Estes, por sua vez, são construídos por meio do diálogo, nem sempre consensual, com as formas de adesão aos princípios de ação da prática profissional expressos pelo profissionalismo.

No caso dos professores que atuam ou vão atuar na educação profissional essa relação entre a construção da profissionalidade e os aspectos mais amplos da profissionalização se complexifica uma vez que a identidade profissional inicialmente adquirida pelos sujeitos é a oriunda da formação de bacharel e a identidade docente vai sendo construída tomando por base diversos elementos que nem sempre rompem com a visão bacheralizante sob as quais aqueles foram formados.

Além desse aspecto, em termos de saberes e conhecimentos necessários para a atuação na educação profissional existe um elemento também não muito consensuado nos outros níveis e modalidades nos quais os professores atuam. Tomamos por exemplo o de que no caso do ensino superior e no ensino nas diversas áreas de currículo da educação básica a atuação e formação docente são definidas pelo recorte disciplinar legitimando assim uma lógica de que quem domina os conteúdos dessas áreas, consequentemente, é um "bom" professor. Esse aspecto é visto por Roldão quando analisa alguns descritores para a profissão docente. Em relação ao "reconhecimento da função e ao saber específico indispensável ao desenvolvimento da atividade e sua natureza", um desses descritores analisados por esta autora, a visão de professor, aceita por muitos durante muito tempo, foi a daquele que "dá aulas" sobre o conteúdo de alguma área ou disciplina, ou como um especialista de uma ou mais disciplinas, ou seja, como aquele que "professa um saber". Segundo essa visão, adicionada às complexas relações sociais e ao processo de construção desses conhecimentos, a autora defende que a função de ensinar é redefinida como "saber fazer aprender alguma coisa a alguém" (ROLDÃO, 2007, p. 17). E nesse sentido vai apontar que existe um consenso sobre a importância da busca do domínio do conhecimento dos conteúdos disciplinares e do conhecimento pedagógico para a formação e atuação do professor.

Essa perspectiva de integração de diferentes saberes considera que "dominar" o conteúdo específico não garante uma prática pedagógica eficaz (TARDIF, 2000; GUATHIER, 2006; PIMENTA, 2005). Busca, também, problematizar uma questão que tem permeado historicamente a profissão de professor, uma vez que durante muito tempo a profissão de professor esteve associada a uma atividade pautada pela ênfase na transmissão de conteúdos, correspondendo ao ensino o ato de professar conteúdos prontos e inquestionáveis, reforçando, assim, a máxima: "quem sabe, sabe ensinar". Segundo Roldão (2010), é muito tardiamente que o "saber sobre o como ensinar" - os saberes pedagógicos e didáticos - assumiu alguma visibilidade. Além desse aspecto, os referenciais simbólicos largamente disseminados sobre o professor como um missionário ou um militante 
social ou esse sábio dotado de poder, dentre outros referencias, têm contribuído, segundo Roldão (2010), para "uma polissemia relativamente ao saber que vale, socialmente, como saber próprio do docente" (2010, p. 28).

Assim, consideramos que os discursos oficiais expressados pelos requerimentos exigidos para a seleção e o ingresso na carreira referentes à formação e o exercício do professor que lecionará na educação profissional é uma dos referenciais que se tem para se compreender a construção da profissionalidade docente para essa modalidade de ensino. Nesse sentido Gatti et al (2011) tem analisado que são poucos ainda os estudos que analisam os concursos públicos para o ingresso na carreira do magistério e destaca, a partir de suas análises que não tem sido muito inovador o caráter que tem sido apresentado nos certames. Na maioria dos casos exigi-se predominantemente nas provas objetivas os conhecimentos dos fundamentos da educação e da legislação educacional como também não há grandes modificações em relação às etapas dos concursos prevalecendo sempre as mesmas.

Partimos do pressuposto de que há um distanciamento significativo do que se propõe nestes discursos oficiais ou seja entre os conhecimentos exigidos nos editais dos concursos e as condições concretas de trabalho do docente da educação profissional e a construção de sua profissionalidade se dá de modo a atenuar e consolidar o atendimento às reais necessidades do ser fazer profissional. Parece ainda que as relações estabelecidas nas instituições em que lecionam podem se configurar em modos diferenciados de vivenciarem a profissão de professor.

Nesse sentido, passa a ganhar relevância a análise da profissionalidade docente, uma vez que esta resgata as particularidades do vivenciar a profissão em contextos específicos, tais como aqueles que caracterizam as especificidades de trabalho com determinado nível de ensino. Para Guerrero (1996 apud CUNHA, 2006), a diferença na formação e na autonomia do professorado depende diretamente do grau de ensino onde atua.

Desde a LDB 9394/96 o ingresso na carreira do magistério é indicado por meio do curso público de provas e títulos, assim este instrumento assume a dupla função de aprimorar a formação e desenhar um exercício docente que se almeja efetivar, além de elevar o processo de profissionalização. O qual no caso dos professores do ensino técnico e tecnológico tem sido marcado pela existência de títulos precários que dão a licença para lecionar nesta modalidade de ensino. Desta feita, tomamos os concursos públicos de ingresso na carreira docente como um dos elementos definidores de uma profissionalidade a ser constituída na docência na educação profissional.

Passemos, então, a apresentação dos dados que se pode analisar até o presente momento.

\section{ANÁLISE DOS EDITAIS DOS CONCURSOS PARA DOCENTES NA EDUCAÇÃO PROFISSIONAL: QUESTÕES INICIAIS}

Com o intuito de caracterizar os concursos públicos para o ingresso de docentes na educação profissional realizamos uma análise documental dos editais dos certames efetivados no período de 2008 a 2012. Desta feita, identificou-se uma média de realização de 2,2 concursos no período estudado conforme tabela a seguir: 
Tabela 01: Concursos para ingresso docente na educação profissional federal- centro-oeste

\begin{tabular}{c|c}
\hline INSTITUIÇÃO & EDITAL/ANO \\
\hline \multirow{2}{*}{ IFMS } & 2009 \\
\cline { 2 - 2 } & 2010 \\
\cline { 2 - 2 } & 2011 \\
\hline \multirow{2}{*}{ IFB } & 2012 \\
\cline { 2 - 2 } & 2009 \\
\cline { 2 - 2 } & 2010 \\
\hline IFGOIÁS & 2012 \\
\hline \multirow{2}{*}{ IFGOIANO } & 2010 \\
\cline { 2 - 2 } & 2010 \\
\hline IFMT & 2011 \\
\hline
\end{tabular}

Fonte: Pesquisa PIBITI-UnB Edital 2012-2013

$\mathrm{O}$ acesso aos editais se deu basicamente nos sítios institucionais dos IF's nos quais coletamos também os resultados gerais em cada um deles para uma análise posterior sobre o desempenho dos candidatos que foram selecionados em cada uma das etapas.

Inicialmente, menciona-se que esses editais possuem certas similaridades o que referendaria a noção de "rede" que se pretende consolidar mediante a promulgação da lei 11892/08 que institui a rede nacional de educação profissional. Depreende-se, nesse sentido, de que não pode haver discrepâncias entre os editais das diferentes instituições e, principalmente, daquelas que compõem uma mesma região política do país para se garantir uma consonância e coerência em relação aos critérios de seleção dos docentes, exigindo-se assim etapas e conhecimentos similares.

Esse aspecto garantiria também um trânsito entre os institutos de possíveis candidatos aprovados que venham, por ventura, serem aproveitados entre os institutos para serem admitidos. Esse aspecto referenda ainda um elemento relevante de profissionalização de modo a fortalecerse o perfil de professores que se quer admitir numa instituição de educação profissional, como também consolida o processo de afirmação de elementos da profissão docente de qualquer outro professor que atue em diferentes níveis e modalidade da educação geral.

Assim, geralmente, os editais apresentam três etapas principais. A primeira composta por uma prova escrita objetiva e ou discursiva na qual o conhecimento exigido geralmente recebe a indicação de "conhecimento específico" denotando ser aquele referente à área de formação dos bacharéis e licenciados nas diversas disciplinas da educação básica. Faz parte também dessa etapa a indicação dos "conhecimentos básicos", estes geralmente sendo os de língua portuguesa e da legislação da educação profissional e ou da legislação federal.

Com menor ocorrência, em apenas um edital, o do IF Goiás/2010, foi indicado como conhecimento comum a todos as áreas, alguns conteúdos referentes à função social da escola, princípios da interdisciplinaridade, projeto político pedagógico, Política de Inclusão escolar, Métodos e técnicas de ensino, Sistema de avaliação escolar e ensino, Parâmetros Curriculares Nacionais e LDB 9394/96, além da Legislação específica da educação profissional. Percebe-se, então, que há uma cisão entre os conhecimentos pilares para a formação docente, na perspectiva de Roldão (2010), nesse caso, o conhecimento específico parece ter lugar de destaque em detrimento aos conhecimentos didático-pedagógicos. Além disso, parece também ficar subentendido, pela predominância da exigência do conhecimento sobre a legislação específica da 
educação profissional (aspecto que aparece em todos os editais estudados), que esta se equivaleria de forma completa aos conhecimentos didático-pedagógicos necessário à atuação docente. Com isto não se quer dizer que tal conhecimento não seria relevante para quem pleiteia atuar na educação profissional, mas, que tal limitação constatada fragilizaria em muito a vertente dos conhecimentos didático-pedagógicos de modo a consolidar a profissionalidade docente para aquele contexto de ensino.

Outro aspecto que reforçaria essa cisão é o destaque dado aos conhecimentos específicos das áreas de formação nos editais que indicavam a realização de prova discursiva. Estas geralmente possuíam uma média de três questões abertas que versavam dos conhecimentos específicos do programa destinado a cada uma das áreas.

A segunda etapa recebe a denominação de "Prova de desempenho didático" onde ocorrea a indicação do conhecimento exigido como conhecimento "didático-pedagógico" ou "didática docente". Nesse sentido, apenas em dois editais do Instituto federal de Brasília (anos de 2009 e 2010) e em dois do Instituto federal Goiano (anos de 2010 e 2011) foram descritos de forma detalhada os critérios a serem avaliados nessa etapa do concurso como também o que deveria figurar no plano de aula entregue pelo candidato à banca examinadora. Nos demais ou havia total inexistência destes critérios ou se indicavam de forma genérica, aspectos como: avaliar conhecimento e didática docente.

É importante destacar que em dois editais do Instituto federal de Brasília (anos de 2009 e 2010) fora indicado que na composição da banca examinadora da prova de desempenho didático haveria a participação de um profissional da educação definido como licenciado, pedagogo ou pósgraduado em educação. Esse pode ser considerado um aspecto relevante na construção da profissionalidade docente uma vez que a avaliação dos pares para o ingresso na carreira pode ser considerado um elemento fortalecedor da profissão. E que no caso da educação profissional pode atenuar o distanciamento, já destacado neste texto, entre o reconhecimento do profissional bacharel com a identidade necessária para atuar na docência. Ou seja, no processo de seleção entre pares estariam melhor delineados os saberes socialmente reconhecidos de modo a diferenciar o docente daqueles que possuem um conteúdo disciplinar em sua formação. Esse processo seria similar ao que já ocorre para o ingresso no magistério superior e segundo Roldão (2005) reforçaria o caráter científico que geraria um grau de autonomia profissional, elemento esse que endossa um processo de profissionalização mais consistente.

No geral, essas primeiras etapas, a da prova escrita e a de desempenho didático, são eliminatórias estipulando-se uma proporcionalidade entre a quantidade de candidatos aprovados e a classificação sob um quantitativo de vagas definidos com critérios de desempate. Dentre estes, o de maior peso seria o desempenho do candidato em relação ao conhecimento específico. Nesse contexto, pretende-se numa outra etapa da pesquisa perceber a relação entre o desempenho do candidato em relação ao conhecimento específico e o que se considera conhecimento pedagógico na prova escrita bem como sua progressão na segunda etapa denominada de desempenho didático.

A terceira etapa dos concursos é a "prova de títulos". Sabe-se que esta é uma prerrogativa apontada constitucionalmente e é referendada pela LDB 9394/96 em seu artigo. Esse elemento dentro do processo de profissionalização docente pode ser considerado um ganho para a profissão, contudo, no caso do professor da educação professional desvela uma certa precariedade 
na construção de sua profissionalidade. Essa precarização se expressa pela indefinição do requisito básico para a sua admissão na carreira docente nessa modalidade. Na verdade esse professor está situado na fronteira entre ser professor da educação básica e ser professor do ensino superior. Sabe-se que, conforme a referida LDB 9394/96 é o curso de licenciatura que habilita o ingresso na carreira (art. 62). Já para o ensino superior o requisito básico seria os cursos de mestrado e ou doutorado (art. 66). Assim, nem todo o perfil de formação do professor selecionado para atuar no ensino técnico e tecnológico atende a tais requisitos o que gera ambiguidades e lacunas. Essa demanda é ainda acentuada com a proposição do princípio da verticalização apontado na lei da rede federal de educação profissional ao qual requer do professor transitar no ensino em cursos de formação inicial e continuada, nos cursos e ensino médio integrados, nos cursos de graduação chegando até a pós-graduação. Essa demanda exige assim a construção de uma profissionalidade particular que estaria assim fragilizada desde os cursos de formação como também nos requisitos básicos apontados ou silenciados nos editais e que não são atendidos de forma plena para o ingresso no magistério.

Nessa mesma linha a despeito dos avanços que o professor do ensino técnico e tecnológico nos últimos anos e em especial com a lei no 12772/2012 que versa sobre a carreira do magistério superior e do professor do Ensino Básico, Técnico e Tecnológico e sobre o Plano de Carreiras de Magistério do Ensino Básico Federal que trouxeram ganhos salariais significativos e corrigiram a diferenciação existente entre a carreira desses tipos de professores, o que se observa é um distanciamento entre os ganhos da política de encarreramento e as necessidades do ensino com diferentes finalidades e objetivos no mesmo contexto da educação profissional.

Foi observado que nos últimos editais entre 2010 e 2012 foram sendo delineados nas provas de títulos critérios que se aproximariam à definição de um perfil de pesquisador muito semelhante ao professor do magistério superior, o que também se justifica pela nova natureza administrativa dos institutos em serem autarquias de ensino superior. Assim, são pontuadas experiências de pesquisa de forma ampliada equivalendo à produção bibliográfica de gêneros diversos (artigos, livros, palestras e etc, a experiência na participação e orientação de pesquisas, bem como na produção de patentes. Observou-se ainda uma oscilação entre a pontuação obtida pela experiência no magistério e a experiência profissional na área de formação inicial, principalmente dos bacharéis. Ora a experiência no magistério é pontuada de forma equivalente e ora é subvalorada em relação à experiência profissional na área de formação inicial. Somente em apenas dois editais a experiência no magistério foi considerada com maior pontuação. Foi interessante identificar a referência em três editais, os do IF Mato grosso à pós-graduação em educação como passível de se atribuir pontuação. Nesses mesmos editais conclusão de créditos adquiridos nas disciplinas dos cursos de mestrados e doutorado também recebia pontuação, sem ser necessariamente, na área de educação.

\section{ALGUMAS CONSIDERAÇÕES FINAIS}

Este estudo está em uma fase inicial e não teve a pretensão de trazer dados ampliados, contudo, a partir do que foi apresentado, parece nos indicar muitos desdobramentos interessantes.

Por exemplo, a dados iniciais destacam assim a ênfase dada aos conhecimentos específicos das áreas de formação dos bacharéis e dos licenciados nas diversas áreas do currículo da educação 
básica em detrimento aos conhecimentos didático-pedagógicos precisa ser melhor analisada à luz dos estudos já consolidados sobre identidade e saberes docentes realizados no contexto da educação profissional.

Assim, como a construção de um perfil de pesquisador para o docente que irá atuar nessa modalidade precisa ser melhor vista articulada ao próprio processo da nova institucionalidade dos institutos federais.

Bem como a precaridade gerada pela indefinição ou ambigüidade quanto à titulação básica, habilitação pela via da licenciatura e ou a realização de curso de mestrado e doutorado pode ser aprofundada a partir do incentivo para a construção de novos perfis de concurso que podem instituir novas etapas inclusive de cursos de formação durante o processo dos certames.

\section{AGRADECIMENTO}

Agradecemos à bolsista de iniciação científica, Nina Daya Simões, por sua contribuição com a coleta de dados.

\section{REFERENCIAS BIBLIOGRÁFICAS}

1. AMBROSETTI, N. B.; ALMEIDA, P. C. A. A constituição da profissionalidade docente: tornar-se professora de educação infantil. 2007. Disponível em http://30reuniao.anped.org. br/trabalhos/GT08-3027--Int.pdf. Acesso em: 10 de setembro de 2008.

2. Brasil. Senado Federal. Lei de Diretrizes e Bases da Educação Nacional: no 4024/61. Brasília: 1961.

3. BRASIL. Senado Federal. Lei de Diretrizes e Bases da Educação Nacional: no 5692/71. Brasília: 1971

4. BRASIL. Lei no 9394 de 20 de dezembro de 1996. Institui as diretrizes e bases da educação nacional. 1996.

5. BRASIL. MEC/Conselho Nacional de Educação. Resolução CP/CNE no 02 de 26 de junho de 1997. Dispõe sobre os programas especiais de formação pedagógica de docentes para as disciplinas do currículo do ensino fundamental, do ensino médio e da educação profissional de nível médio. Brasília: Diário Oficial da União, 15 jul. Seção I.

6. CUNHA, M. I. Trabalho docente e profissionalidade na universidade. Revista de Estudos curriculares, Porto, Ano 4, no 1, 2006, 67-84. DOURADO, L. F. Políticas e gestão da educação básica no Brasil: limites e perspectivas. Educ. Soc. [online]. 2007, vol. 28, no. 100, pp. 921-946. Disponível em: http://www.scielo.br/scielo.php?script=sci_arttext\&pid=\$0101-7330200700 0300014\&lng=pt\&nrm=iso

7. GATTI, Bernadete, BARRETO, Elba de sá, LUDKE,Menga. Políticas de formação docente no Brasil, Unesco, 2012.

8. GUATHIER, C. et al. Por uma teoria da Pedagogia. Ijuí, RS: Ed. Unijuí, 2006.

9. PIMENTA, Selma Garrido (org.). Saberes pedagógicos e atividade docente. São Paulo:Cortez, 2005.

10. MACHADO, Lucília Regina de Souza. O desafio da formação de professores para a EPT e 
PROEJA. Educ. Soc., Campinas, v. 32, n. 116, p. 689-704, jul.-set. 2011. Disponível em < http://www.cedes.unicamp.br/ >

11. ROLDÃO, Maria do Céu. Profissionalidade docente em análise - especificidades dos ensinos superior e não superior. Nuances: estudos sobre educação. São Paulo, Ano XI, v. 12, n.13, jan/dez, 2005. 105-126 p.270

12. Formar para a excelência profissional - pressupostos e rupturas nos níveis iniciais da docência. Educação \& Linguagem. Programa de Pós-Graduação em Educação: Universidade Metodista de São Paulo, Ano 10, no 15, jan-jun, 2007, 18-42.

13. . Formação de professores na investigação portuguesa - um olhar sobre a função do professor e o conhecimento profissional. Revista Brasileira de Pesquisa sobre formação docente. Belo Horizonte, v.01, p.57-70. Ago/dez 2009. Acesso em jul/2010.

14. Ensinar e aprender: o saber e o agir distintivos do profissional docente. In: ENS, Romilda Teodora; BEHRENS, Marilda Aparecida (orgs.). Formação do professor: profissionalidade, pesquisa e cultura escolar. Curitiba: Editora Champagnat, 2010. p. 25-42. 